\title{
Antibiotic Use and Resistance for Beef Cattle Producers $^{1}$
}

\author{
Chad Carr, Matt Hersom, K. C. Jeong, Nicolas DiLorenzo, Jason Scheffler, Gina Faniola, \\ Stephanie Miller, Haley Denney, Victoria Roberts, Nahilia Williams, Bianca McCracken²
}

Recent work at UF/IFAS has shown that antibiotic-resistant bacteria can be present at a farm even if that farm uses no antibiotics. Some level of antimicrobial resistance is natural, and some threshold level of resistance will be present on every farm, but cattle producers can still work against antibiotic-resistant microorganisms (ARMs) by avoiding overuse of antibiotics and following best management practices to keep animals and people as healthy as possible.

\section{Why are antibiotic-resistant microorganisms important} to understand?

Over 2 million illnesses and 23,000 human deaths are estimated to be caused by antibiotic-resistant microorganisms (ARMs) in the United States each year (US HHS-CDC 2013). The healthcare costs in the United States for ARMs are estimated at 2 billion dollars annually (Thorpe et al. 2018).

\section{What are ARMs and resulting antibiotic resistance?} Susceptible bacteria die when antibiotics are administered. Most of the bacteria left alive after administration of antibiotics are resistant to the antibiotic: antibiotic-resistant microorganisms, or ARMs. When these ARMs reproduce, they proliferate their antibiotic-resistant genes in a process typically called "vertical gene transfer" within their environment, spreading these genes and increasing the problem (Soucy et al. 2015, Belk 2018, and Mir et al. 2018).
Because the use of any antibiotic selects for a population of ARMs, it has been suggested (Vieira et al. 2011, Mir et al. 2018) that the use of antibiotics in food production is partially responsible for the spread of ARMs in the environment, residences, and healthcare facilities. Antibioticresistant microorganisms can exist in the absence of antibiotics or antibiotic residues.

\section{Are ARMs the same as an antibiotic residue?}

No, they are completely different phenomena. Livestock treated with antibiotics must observe a mandated withdrawal period to allow antibiotics to clear from their system before milk or meat from that animal are marketed. Livestock cannot be marketed if residual antibiotics in their meat or milk exceed permitted levels. Instances of an antibiotic exceeding the maximum allowable chemical concentration in an animal tissue are very low in the developed world, particularly in the United States (USDAFSIS 2017).

\section{Have ARMs only developed since the development of antibiotics in the $20^{\text {th }}$ century?}

No. Antibiotic resistance is inherent in nature. Most antibiotics are derived from microorganisms found in soil. The natural presence of an antibiotic in the soil results in selection for ARMs. For example, D'Costa et al. (2011) identified 30,000-year-old actinobacteria in permafrost, which is a thick layer of frozen soil, and the ancient bacteria contained genes encoding resistance to multiple antibiotics.

1. This document is AN351, one of a series of the Animal Sciences Department, UF/IFAS Extension. Original publication date January 2019. Visit the EDIS website at https://edis.ifas.ufl.edu for the currently supported version of this publication.

2. Chad Carr, associate professor; Matt Hersom, associate professor; K. C. Jeong, associate professor; Nicolas DiLorenzo, associate professor; Jason Scheffler, assistant professor, UF/IFAS Department of Animal Sciences, UF/IFAS Extension; Victoria Roberts, Nahilia Williams, and Bianca McCracken, FAMU Animal Sciences alumni and interns with the USDA/NIFA Antimicrobial Resistance Project; Gina Faniola, Stephanie Miller, Haley Denney, UF/IFAS Department of Animal Sciences alumni and interns with the USDA/NIFA Antimicrobial Resistance Project; UF/IFAS Extension, Gainesville, FL 32611

The Institute of Food and Agricultural Sciences (IFAS) is an Equal Opportunity Institution authorized to provide research, educational information and other services

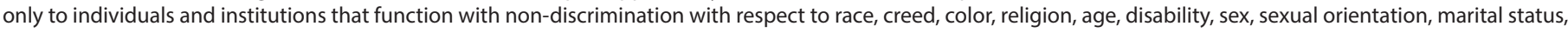

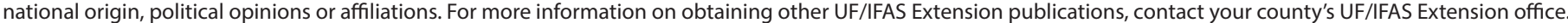
U.S. Department of Agriculture, UF/IFAS Extension Service, University of Florida, IFAS, Florida A \& M University Cooperative Extension Program, and Boards of County Commissioners Cooperating. Nick T. Place, dean for UF/IFAS Extension. 
How are antibiotics used in livestock production?

Antibiotics are used in four major ways in agriculture (Schwarz et al. 2001). Therapeutic antibiotics are used to treat a diagnosed disease. Prophylactic antibiotics are used to prevent disease. Metaphylactics are administered to an entire herd or flock to prevent the spread of disease. Growth promotion is the fourth major use. Criticism of the use of antibiotics purely for growth promotion has led many countries, including the United States, to restrict or ban the use of antibiotics for growth promotion.

What percentage of antibiotics used for animals is determined to be “important for human health?" According to the FDA's 2016 estimates, 58\% (Figure 1). Tetracycline is by far the predominant antibiotic drug class used in US animal populations. Tetracycline is an antibiotic drug class that accounts for less than $5 \%$ of human use in the United States (US-FDA 2017).

\section{What about the media statements that $70 \%$ of the} antibiotics determined "important for human health" are actually used for animals?

The FDA highly discourages those statements. It is technically true that more antibiotics are given to livestock than are given to humans, but that is because the amount of antibiotics that will be an effective dose for a cow is much larger than the amount that will an effective dose for a human because the cow weighs so much more than the person. The average human adult weighs around 180 pounds compared to a 1,600-pound dairy cow. That cow's dose would treat approximately 9 humans.

\section{Antibiotics Sold for Animals - Key} Categories

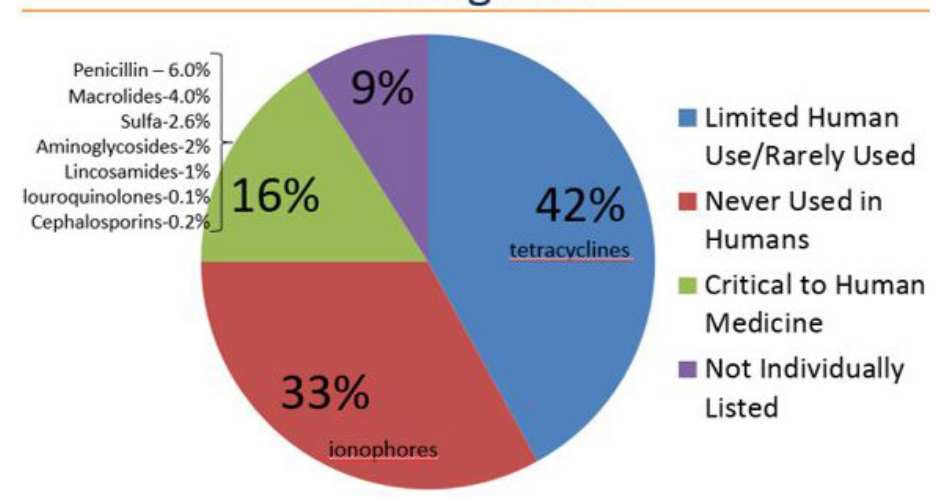

Figure 1. Key animal antibiotics categories. Credits: FDA
The antibiotics we use to treat animals are different from the ones we use to treat humans: why doesn't that keep the human antibiotics effective?

Bacteria with resistance to one type of antibiotic frequently are found to be resistant to other antibiotics as well. A review by Soucy et al. (2015) documents a phenomenon known as horizontal genetic transfer where there is a transfer of genetic material from one microorganism to another of a different species. Also, the means a microorganism uses to survive one antibiotic could potentially incur resistance to another antibiotic. Additionally, a review by Belk (2018) documents how long-term supplementation of a given antibiotic to a market steer during a 150-day feeding period would shift the microflora of the bacteria so that they remain resistant.

\section{How have antibiotics been regulated in other countries and the United States?}

In 1986 and 1999, respectively, concern about proliferating ARMs led the Swedish and Danish governments to ban antibiotic use for growth promotion in food animals (Aarestrup 2003, WHO 2003). The European Commission followed with a similar ban for all EU-member countries in 2006 (European Commission 2005).

The United States followed with a similar regulation in 2017 titled Guidance 213, the Veterinary Feed Directive (VFD; Federal Register 2015; Hersom et al. 2017). The US rule has no impact on injectable antibiotics, rather only those included in feed or water. It disallows the use of antibiotics for growth promotion and encourages the judicious use of medically important feed-grade antibiotics. The US government has introduced this directive as a means of attempting to reduce the livestock industry's contribution to antibiotic resistance (Hersom et al. 2017).

\section{How did Danish and Dutch regulation of antibiotic use} affect ARMs in meat animals and humans?

The Danish government has a very robust database titled DANMAP to track antibiotic use in animals, ARMs from purchased meat, and ARMs in human clinics. Figure 2 shows that no growth-promoting antibiotics were sold in Denmark after 2000, following the 1999 ban. It also shows that more therapeutic antibiotics were prescribed than before the 1999 ban, a trend which has continued (Figure 2). Additional results from DANMAP suggest that the percentage of antibiotic-resistant Salmonella typhimurium isolated from Danish pigs and pork has not decreased since the growth-promotion ban of 1999. This is theorized to be due to the greater use of therapeutic antibiotics. Also, the percentage of antibiotic-resistant Salmonella typhimurium isolated from infected humans since 2008 has not decreased. 
The Netherlands has a similar database titled NETHMAP. Just as in Denmark, no growth-promoting antibiotics have been sold since the 2006 ban (Figure 3). Also as in Denmark, more therapeutic antibiotics were prescribed initially (Figure 3). However, therapeutic antibiotic use has since declined steadily in Dutch food animals. Accordingly, Salmonella typhimurium isolated from cattle, hogs, and people in the Netherlands has become less resistant to antibiotics since 2006 (Figure 4).

In the Danish example, resistance increased with more use of therapeutic antibiotics, but in the Dutch example, resistance appears to be decreasing.

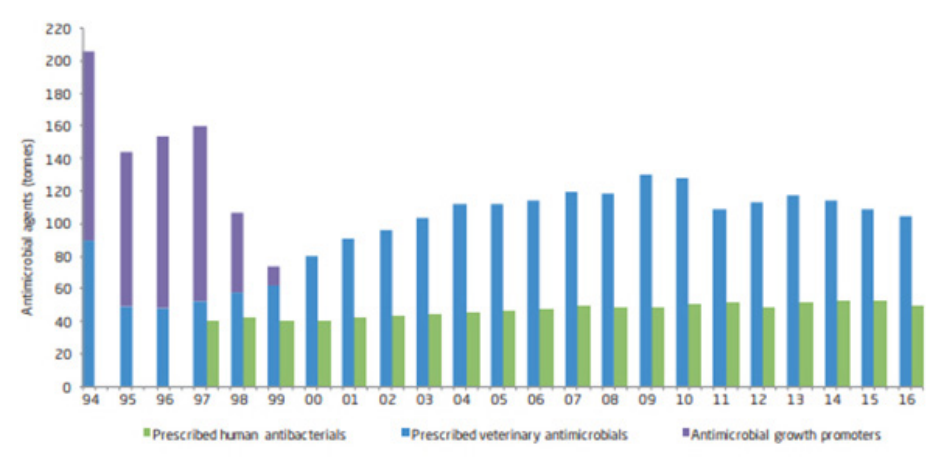

Sources: Human therapeutics: The Danish Health Data Authority. Antimicroblals for animals: Until 2001, data are based on reports from the Pharmaceutical industry of total annual sales from the federation of Danish pig producers and slaughterhouses (1994-1995) and Danish and 22 nd August 2017 ) and includes all antimicrobial agents registered for use in animals.

Figure 2. Prescribed antimicrobial agents for humans and for all animal species in Denmark.

Credits: DANMAP 2017-Use of antimicrobial agents and occurrence of antimicrobial resistance in bacteria from food animals, food and humans in Denmark. ISSN 1600-2032

\section{What impact have US regulations had on the industry?} The FDA reported that less food-animal antibiotics were marketed in 2016 than 2015 (FDA 2017). This was before the VFD became law in January, 2017, suggesting that the industry preemptively reduced sales to prepare for the VFD. It was the first decline in year-to-year sales since the FDA began collecting data of antibiotic sales for animals in 2009 .

\section{What has the University of Florida/IFAS learned?}

Cefotaxime is a third-generation cephalosporin used extensively in human medicine for the treatment of bacterial pneumonias, soft tissue infections, and meningitis. It is on the WHO list of essential medicines (FDA 2012). Bacteria become resistant to cephalosporins by the production of $\beta$-lactamase enzymes, with one of the primary enzymes being extended-spectrum $\beta$-lactamases (ESBLs). Bacteria producing ESBL enzymes are likely resistant to cephalosporins such as Naxcel $^{\circledast}$, Excenel ${ }^{\circledR}$, and Excede ${ }^{\circledR}$ and penicillin (Mir et al. 2016 and 2018).
In a UF/IFAS study, 188 spring-born calves with no exposure to any antibiotics were followed during the first year of life to assess ARMs, specifically cefotaxime-resistant bacteria (CRB). Fecal samples were collected from calves quarterly. Over $92 \%$ of the calves tested positive for CRB at least once during the first year of life, despite never being exposed to any antibiotic (Mir et al. 2018).

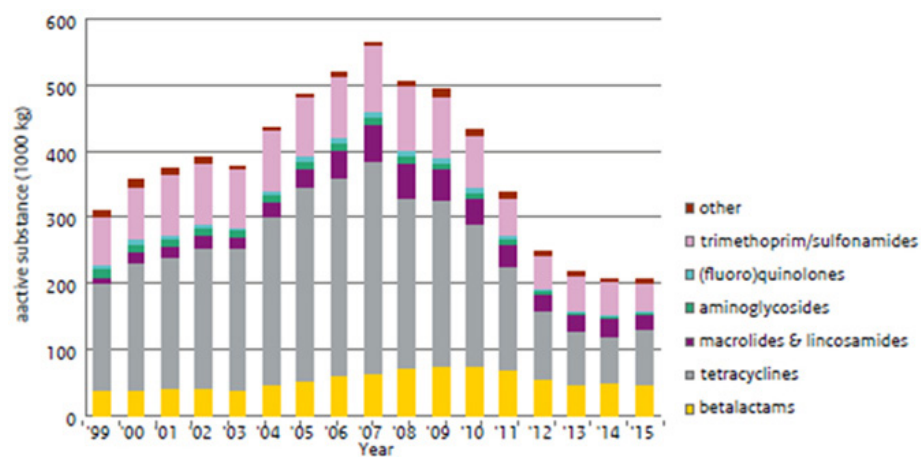

Figure 3. Antimicrobial veterinary medicinal product sales from 1999-2015 in kg (thousands).

Credits: NethMap 2016-Consumption of antimicrobial agents and antimicrobial resistance among medically important bacteria in the Netherlands in 2015
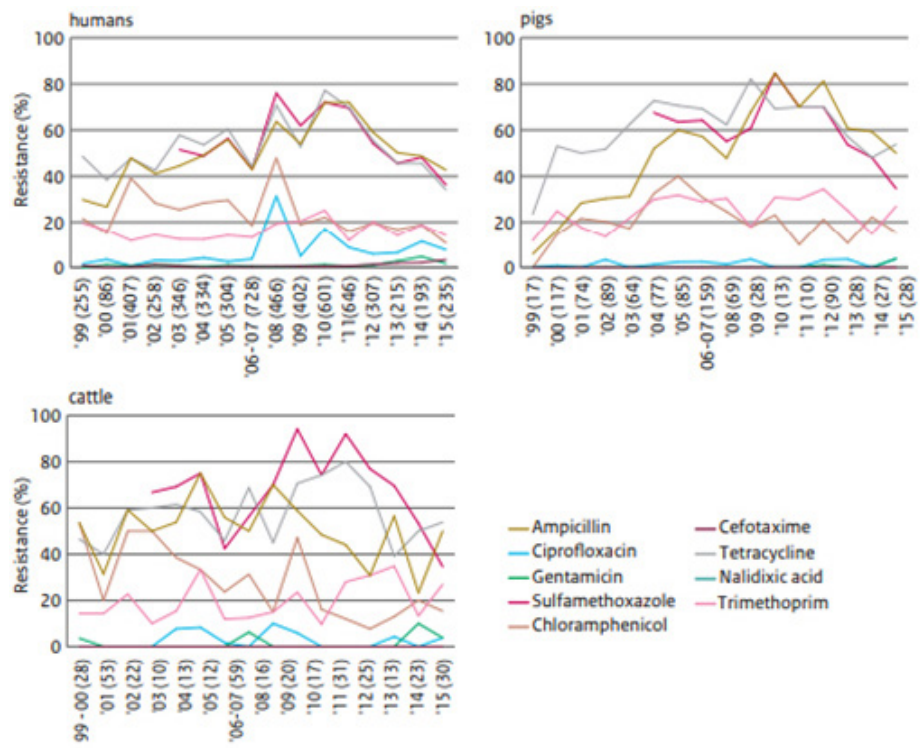

Figure 4. Trends in resistance (\%) of S. typhimurium isolated from humans and food animals in 1999-2015.

Credits: NethMap 2016-Consumption of antimicrobial agents and antimicrobial resistance among medically important bacteria in the Netherlands in 2015

\section{Where did the ARMs come from?}

It is possible that the pathogens could have developed ESBLs through natural evolution of the microbiota in the soil on this farm as described in permafrost (D'Costa et al. 2011). It is also possible ARMs could have been introduced into the soil via vectors such as contaminated bird droppings or municipal wastewater effluents. 


\section{What can I do as a cow-calf producer?}

Very little antibiotics are used at the cow-calf level in the United States, yet results from the work at UF/IFAS suggest a large percentage of US cattle would nevertheless express ARMs. Use antibiotics judiciously when needed, and properly follow label instructions for dosage, administration, and withdrawal period.

\section{Are any antibiotics used in beef feedyards?}

A large percentage of calves receive an injectable metaphylactic antibiotic treatment when they arrive at a feedyard to prevent clinical sickness following the stress of transportation and being exposed to other cattle. Additionally, most cattle are fed an ionophore to control coccidiosis and a macrolide to prevent liver abscesses. Producers and scientists will look for effective alternatives to these technologies to reduce possible establishment of ARMs.

\section{What can I do as a consumer?}

Prevent cross-contamination. Cook meat properly to prevent food-borne illness and inhibit the spread of antimicrobial resistance from any remaining pathogen (Bub et al. 2013).

\section{What do producers and consumers need to know?} Antibiotic resistance is a complicated issue. The recent work here at UF/IFAS documents that antibiotic-resistant bacteria can be present at a farm even if that farm uses no antibiotics. There is evidence that some level of antimicrobial resistance is natural, and some threshold level of resistance will be present on every farm. Producers and managers must use antibiotics sparingly and judiciously to minimize antimicrobial resistance.

\section{Literature Cited}

Aarestrup, F. M. 2003. "Effects of termination of AGP use on antimicrobial resistance in food animals." Pages 6-11 in Working papers for the WHO international review panels evaluation. Document WHO/CDS/CPE/ZFK/2003.1a. World Health Organization, Geneva, Switzerland.

Belk, K. E. 2018. "Alternatives to long-term treatment with antibiotics in feed." National Cattlemen. 8.

Bub, E. L., K. Schneider, C. C. Carr. and M. Hersom. 2013. Food Processing: The Meat We Eat. AN283. Gainesville: University of Florida Institute of Food and Agricultural Sciences. http://edis.ifas.ufl.edu/an283
DANMAP. 2016. Use of antimicrobial agents and occurrence of antimicrobial resistance in bacteria from food animals, food and humans in Denmark. https://www. danmap.org/-/media/arkiv/projekt-sites/danmap/danmapreports/danmap-2016/danmap_2016_web.pdf?la=en

D'Costa, V. M., C. E. King, L. Kalan, M. Morar, W. W. Sung, C. Schwarz, D. Froese, G. Zazula, F. Calmels, R. Debruyne, and G. B. Golding. 2011. "Antibiotic resistance is ancient." Nature 477 (7365), p.457.

European Commission. 2005. Ban on antibiotics as growth promoters in animal feed enters into effect. http://europa. eu/rapid/press-release_IP-05-1687_en.htm

Federal Register. 2015. Wednesday, June 3, 2015. Rules and Regulations. Federal Register 80(106): 31708-31735.

Hersom, M., T. Thrift, and J. Yelich. 2017. AN327. How the Veterinary Feed Directive Affects Cattle Owners. Gainesville: University of Florida Institute of Food and Agricultural Sciences. http://edis.ifas.ufl.edu/an327

Mir, R. A., T. A. Weppelmann, J. A. Johnson, D. Archer, J. G. Morris Jr, and K. C. Jeong. 2016. "Identification and Characterization of Cefotaxime Resistant Bacteria in Beef Cattle." PLoS ONE 11(9): e0163279. doi: 10.1371/journal. pone .0163279

Mir, R. A., T. A. Weppelmann, L. Teng, A. Kirpich, M. A. Elzo, J. D. Driver, and K. C. Jeong. 2018. "Colonization Dynamics of Cefotaxime Resistant Bacteria in Beef Cattle Raised Without Cephalosporin Antibiotics." Frontiers in Microbiology 9, 500 .

NethMap. 2016. Consumption of antimicrobial agents and antimicrobial resistance among medically important bacteria in the Netherlands. https://www. wur.nl/upload_mm/0/b/c/433ca2d5-c97f-4aa1-ad34a45ad522df95_92416_008804_NethmapMaran2016+TG2. pdf

Schwarz, S., C. Kehrenberg, and T. R. Walsh. 2001. "Use of antimicrobial agents in veterinary medicine and food animal production." International Journal of Antimicrobial Agents 17(6), 431-437.

Soucy, S. M., J. Huang, and J. P. Gogarten. 2015. "Horizontal gene transfer: building the web of life." Nature Reviews Genetics 16 (8), p.472. 
Thorpe, K. E., P. Joski, and K. J. Johnston. 2018. “AntibioticResistant Infection Treatment Costs Have Doubled Since 2002, Now Exceeding \$2 Billion Annually." Health Affairs $37(4), 662-669$.

USDA Food Safety and Inspection Service. 2018. National residue program for meat, poultry, and egg products. https://www.fsis.usda.gov/wps/wcm/connect/93ae550c6fac-42cf-8c11-006748a4d817/2017-Red-Book. pdf?MOD=AJPERES

US HHS-CDC. 2013. https://www.cdc.gov/drugresistance/ pdf/3-2013-508.pdf

US-FDA. 2012. "Use and Importance of Cephalosporins in Human Medicine." Federal Register 77, 735-745. Available online at: https://www.govinfo.gov/content/pkg/FR-201201-06/pdf/2012-35.pdf

US-FDA. 2017. Antimicrobials Sold or Distributed for Use in Food-Producing Animals. https://www.fda.gov/downloads/forindustry/userfees/animaldruguserfeeactadufa/ ucm588085.pdf

Vieira, A. R., P. Collignon, F. M. Aarestrup, S. A. McEwen, R. S. Hendriksen, T. Hald, and H. C. Wegener. 2011. "Association between antimicrobial resistance in Escherichia coli isolates from food animals and blood stream isolates from humans in Europe: an ecological study." Foodborne Pathogens and Disease. 8 (12), 1295-1301.

World Health Organization. 2003. Impacts of antimicrobial growth promoter termination in Denmark. Pages 1-57 in Document WHO/CDS/CPE/ZFK/2003.1. WHO, Foulum, Denmark. 